\title{
GRUPO DE APOIO AO ACOMPANHANTE DO TRANSPLANTADO DE MEDULA ÓSSEA: UMA CONTRIBUIÇÃO À PRÁXIS GRUPAL*
}

\author{
Érika Arantes de Oliveira \\ Luciana Marchetti Torrano-Masetti \\ Manoel Antônio dos Santos ${ }^{1}$
}

\begin{abstract}
RESUMO: O paciente que se submeterá ao transplante de medula óssea (TMO) permanece internado em uma enfermaria onde, além de cuidados especiais, necessita de um acompanhante em tempo integral. Sobre esta pessoa, em quem já pesou o impacto do diagnóstico e a decisão do transplante, agora recai a responsabilidade de auxiliar o paciente no seu tratamento. Na tentativa de amenizar as angústias desencadeadas por esse processo no acompanhante do transplantado foi instituído, na Unidade de TMO do Hospital das Clínicas de Ribeirão Preto, um grupo de apoio psicológico. $O$ presente estudo foi realizado com o objetivo de descrever o processo grupal e averigüar os seus efeitos nos acompanhantes. O corpus foi constituído por 40 sessões, transcorridas no período de seis meses, envolvendo 17 participantes. Estas sessões foram transcritas e analisadas de acordo com uma abordagem qualitativa, aplicando-se uma análise de conteúdo temática nos segmentos dos relatos verbais. O material foi submetido à avaliação independente de dois juízes. Os resultados apontam a efetividade do grupo como recurso para apoio psicológico, uma vez que permite aos acompanhantes compartilharem suas emoções com pessoas que vivenciam uma situação semelhante, ao mesmo tempo em que se sentem compreendidos e amparados por um profissional da equipe.
\end{abstract}

Palavras-chave: acompanhante, grupo de apoio a familiares, transplante de medula óssea, psico-oncologia.

\section{SUPPORTIVE GROUP FOR CAREGIVERS OF BONE MARROW TRANSPLANTATION RECIPIENTS: A CONTRIBUTION TO GROUP PRAXIS}

\begin{abstract}
The patient who will go through a BMT stays in a ward where, besides special care, he needs a full-time caregiver. The diagnosis impact and the decision to have the transplantation done have already weighted, and weighted a lot on this person and now he has to cope with all the responsibility that comes on him. Aiming to relief the caregiver anguish unchained by the BMT process, a psychological supportive group was established, at BMT Unit at Hospital das Clínicas, in Ribeirão Preto (Brazil). In order to describe the group process and check its effects on caregivers, the present study was carried out. The corpus was formed by 40 sessions, developed in a period of six months and having 17 participants. These sessions were transcribed and analyzed in a qualitative approach. Further, a thematic content analysis was applied to the oral report segments. The material was submitted to two, independently, judge evaluation. The results show effectiveness of the group as a psychological support resource, once the group allows caregivers to share their emotions with people who go through similar situation and at the same time they feel understood and supported by the professional staff.
\end{abstract}

Key words: caregiver, family supportive group, bone marrow transplantation, psycho-oncology.

O fato de ter um familiar com o diagnóstico de câncer traz obviamente inúmeras repercussões dolorosas, atingindo não somente o indivíduo que é acometido por tal enfermidade, como toda a sua unidade familiar (Rivera, 1997). Nesse momento, as famílias enfrentam a perda da vida "normal", tal como era antes do diagnóstico, sendo obrigadas a fazerem o luto pela perda da condição de vida que tinham enquanto unidade familiar antes da doença, bem como o luto decorrente da perda dos sonhos e da esperança depositada no futuro. Além disso são obrigados a encarar a dissolução do mito familiar de que as doenças fatais só acontecem com os outros (Rolland, 1998).

Endereço para correspondência: Av. Bandeirantes, 3900 - 14049-901 - Ribeirão Preto - SP. E-mail: masantos@ffclrp.usp.br

Paidéia, FFCLRP-USP, Rib. Preto, junho/99. 
É nesse momento do impacto gerado pela comunicação do diagnóstico que inicia-se, para a família, o processo de perda do ente querido, especialmente tratando-se da descoberta de uma doença com um prognóstico tão reservado como $e$ o câncer. Em uma situação como esta, o diagnóstico traz consigo o temor da possibilidade da morte. Para muitos essa possibilidade transforma-se em certeza e, consequentemente, o diagnóstico converte-se em sentença de morte.

Esse processo de descoberta e posterior acompanhamento pela família do tratamento do paciente é de tal modo estressante, que em muitas circunstâncias as suas necessidades excedem às do paciente, tornando a ansiedade familiar um dos aspectos de mais difícil manejo para a equipe profissional (Higginson, 1993).

Em um paciente com indicaēćo para o Transplante de Medula Óssea (TMO), tratamento especializado indicado para as diversas neoplasias e doenēas hematológicas, essa ansiedade é ainda maior, uma vez que, após o impacto do diagnóstico, os familiares, juntamente com o paciente, devem decidir entre a realizaēćo ou nćo desse procedimento.

Essa opção torna-se extremamente difícil, tendo-se em vista que é transmitido para os familiares, pela equipe de profissionais, a informação de que o transplante é um procedimento intenso, envolvendo consideráveis riscos, e que complicações de difícil controle podem acontecer. Mas, se por um lado essas informações assustam, por outro trata-se da possibilidade da cura, muitas vezes visualizada como a única e última salvação.

Uma vez vencido esse conflito e prevalecendo a opção pela realização do procedimento, o paciente ficará internado em uma enfermaria em isolamento protetor e necessitará de um acompanhante em tempo integral, sendo essa uma exigência do serviço.

Trata-se de uma tarefa muito difícil e desafiadora para quem mantém vínculos afetivos estreitos com o enfermo. Essa pessoa, que na condição de familiar e acompanhante do paciente, já sofrera o impacto do diagnóstico e da decisão do transplante, agora se vê diante de outra responsabilidade, que é auxiliar o paciente no decorrer do tratamento.

Os acompanhanites, tomados muitas vezes pela ansiedade e pela incapacidade de absorver to- das as informações técnicas que Ihe são passadas, freqüentemente acabam não desempenhando satisfatoriamente seu papel, de acordo com as necessidades da equipe e do próprio paciente.

\section{O dispositivo grupal}

$\mathrm{Na}$ tentativa de amenizar o sofrimento vivenciado pelo acompanhante do paciente de câncer internado na enfermaria da Unidade de Transplante de Medula Óssea do Hospital das Clínicas de Ribeirão Preto, foi instituído um grupo aberto de apoio ao acompanhante, composto por no máximo cinco e no mínimo três componentes, coordenado por uma psicóloga e observado por uma psicólogaestagiária. Com a duração de uma hora e frequiência semanal, o grupo vem sendo realizado desde janeiro de 1999, segundo procedimento descrito em estudos anteriores (Torrano-Masetti, Oliveira, Santos, Voltarelli e Simões, 2000).

Optou-se pela modalidade terapêutica grupal, uma vez que, de acordo com Chiattone (1998), os procedimentos realizados em grupos oferecem diversas vantagens, à medida que os integrantes podem vivenciar experiências semelhantes às do seu dia-adia, generalizar com maior rapidez os ganhos adquiridos, entrar em contato com um maior número de situações-problema e visualizar saídas mais condizentes que podem gerar soluções adaptativas. Segundo a autora, o grupo ainda é importante por induzir uma intensa sensação de universalidade, à medida que seus componentes experimentem alívio ao perceberem que não estão sozinhos com seus problemas. Zimerman, Osório e cols. (1997) chamam a atenção para a relevância da prática com grupos no contexto institucional, mostrando as vantagens dessa estratégia de atendimento em serviços de saúde, entre outros.

Desde o nascimento, o indivíduo está habituado a ser integrante de diferentes grupos, a começar do familiar. Um grupo pode ser definido como

“...um conjunto restrito de pessoas que, ligadas por constantes de tempo e espaço, $e$ articuladas por sua mútua representação interna, se propõem de forma explícita ou implícita à realização de uma tarefa que constitui sua finalidade, interatuando para isso através de complexos mecanismos de

Paidéiā, FFCLRP-USP, Rib. Preto, junho/99. 
adjudicação e assunção de papéis" (Osório e cols., 1989, p. 127).

O dispositivo grupal reproduz uma situação de aprendizagem (de papéis, relacionamentos interpessoais, etc.) que o indivíduo realiza cotidianamente em seu processo de adaptação ativa à realidade. A técnica que utilizamos, inspirada no modelo de Grupo Operativo elaborado por Pichón Rivière (1994), constitui um tipo de intervenção psicológica no campo grupal que se centra na tarefa. A tarefa corresponde ao motivo explícito da constituição do grupo (tarefa explícita) e inclui a elaboração das ansiedades básicas que operam como resistência à mudança (tarefa implícita). Essas ansiedades básicas emergem em todo processo ativo de apreensão da realidade quando surgem os primeiros indicíos de mudança. As ansiedades são de dois tipos: omedo de perda do equilíbrio já conquistado (pautas de conduta internalizadas e estruturadas, que organizam os padrões de interação) e medo do ataque da nova situação que está por vir, para a qual o sujeito não se sente instrumentalizado.

O grupo objetiva mobilizar as dificuldades de aprendizagem e comunicação produzidas pelas ansiedades despertadas por todo processo de mudança, dentre os quais se inclui a adaptação à situação de enfermidade. Essa técnica não está centrada nos componentes considerados individualmente, mas no grupo, entendido como

“...um sistema de açōes que surge a partir das necessidades dos integrantes, o que determina a definição de objetivos e de uma tarefa em marcha para alcançá-los. O compartilhar necessidades em função de um objetivo comum é um processo contraditório que faz surgir obstáculos na comunicação, nas relações interpessoais e no conhecimento elaborado pelos integrantes de um grupo. Os obstáculos precisam tornar-se conhecidos para serem resolvidos na ação dos integrantes" (Gayotto, s/d, p. 3).

O processo de mudança inclui ainda a prétarefa e o projeto. A pré-tarefa corresponde à "situação defensiva que estrutura a atitude de resistência à mudança, mobilizada pelas ansiedades de per- da e ataque" (Gayotto, s/d, p. 5). Já o projeto é "a integração que transforma o trabalho grupal em uma criação que vai além do âmbito da tarefa e produz novas possibilidades de ação aos integrantes, situados em seus contextos, comprometidos e inseridos ativamente na realidade" (Gayotto, s/d, p. 5).

Por processo grupal entende-se a dinâmica de funcionamento de um determinado grupo, considerando-se seus marcos referenciais prévios, o interjogo constante de papéis e projeções, e os sistemas de defesa mobilizados para enfrentar os conflitos. Esse conjunto de fatores determina os recursos pessoais que são utilizados na resolução de problemas, incluindo-se aí as atitudes frente a situações de mudança (por exemplo, as resistências que perturbam a aprendizagem a partir das experiências de vida). A apropriação da dimensão processual do grupo é bastante instigante do ponto de vista do contexto da práxis hospitalar porque o próprio conceito de saúde implica, segundo Pichón-Rivière (1994, p. 3), uma noção de processo: "A saúde mental consiste nesse processo, em que se realiza uma aprendizagem da realidade através do confronto, manejo $e$ solução integradora dos conflitos."

O presente estudo surgiu da necessidade de sistematizar o processo de intervenção proporcionado pelo grupo de acompanhantes, baseada em uma postura de revisão crítica permanente a respeito do estatuto das práticas institucionais. Dentro desse contexto, procuraremos caracterizar o processo grupal, descrevendo suas etapas e averiguando seus efeitos sobre os participantes do grupo. Buscaremos captar no aqui-agora-comigo de cada encontro o conjunto de afetos, experiências e conhecimentos com os quais os integrantes do grupo pensam e atuam ao abordarem as questões desencadeadas pela doença, identificando as estratégias empregadas para a comunicação, a aprendizagem, a busca de esclarecimento e a resolução das tarefas que cada etapa do TMO exige.

\section{Método}

\section{Amostra}

Os sujeitos que integraram a amostra do presente estudo foram os acompanhantes dos pacientes da Unidade de Transplante de Medula Óssea, do Hospital das Clínicas de Ribeirão Preto, que inte- 
graram o grupo durante o ano de 1999.

Dos 17 participantes, a maior parte era do sexo feminino $(n=11$, aproximadamente $65 \%)$. Em relação ao grau de parentesco, observou-se uma maior concentração de esposas (cinco, o equivalente a $29 \%$ dos componentes do grupo), seguida por mães, pais e esposos (três participantes, ou 17\%, em cada uma dessas categorias). Aparecem ainda, embora com uma freqüência bem mais discreta, uma tia, uma namorada e uma filha.

A relação dos acompanhantes de acordo com faixa etária e sexo do paciente acompanhado aparece na Tabela 1.

TABELA 1: Distribuição dos acompanhantes de acordo com a faixa etária e a sexo dos pacientes.

\begin{tabular}{cll}
\hline Acompanhantes & \multicolumn{1}{c}{ Parentesco } & Faixa Etária/ Sexo (do paciente) \\
\hline A & \multicolumn{1}{c}{ Tia } & Jovem- Feminino \\
B & Marido & Adulto- Feminino \\
C & Esposa & Adulto- Masculino \\
D & Marido & Adulto- Feminino \\
E & Pai & Jovem- Masculino \\
F & Esposa & Adulto- Masculino \\
G & Mãe & Criança- Feminino \\
H & Mãe & Criança- Feminino \\
I & Esposa & Adulto- Masculino \\
J & Mãe & Jovem- Feminino \\
K & Esposa & Adulto- Masculino \\
L & Esposa & Adulto- Masculino \\
M & Marido & Adulto- Feminino \\
N & Mãe & Jovem- Masculino \\
O & Pai & Jovem- Masculino \\
P & Filha & Adulto- Masculino \\
Q & Namorada & Jovem- Masculino \\
\hline
\end{tabular}

ga exercia a função de coordenadora, enquanto outra atuava como observadora do grupo, registrando as verbalizações emitidas pelos acompanhantes e pela coordenadora, bem como atitudes e comportamentos não verbais. Logo depois de encerrado o grupo, era efetuada a transcrição do material.

As sessões que constituíram o corpus estabelecido no presente estudo transcorreram entre 0 mês de janeiro de 1999 e o mês de outubro desse mesmo ano. $O$ corpus foi constituído por 40 sessões.

Foi empregada uma metodologia qualitativa de avaliação do processo grupal, aplicando-se uma análise de conteúdo temática nos segmentos dos relatos verbais, tomados como unidades de significado, de acordo com os critérios definidos por Bardin (1977), Triviños (1987) e Minayo (1992). O material foi submetido à avaliação independente de dois juízes, ambos profissionais de psicologia com experiência na área, sendo uma psicóloga ligada à Unidade de Transplante de Medula Óssea e um psicólogo não vinculado à instituição hospitalar.

Essa análise permitiu a elucidação do movimento evolutivo do grupo ao longo das sessões, que será apresentado através de alguns recortes que incluem "tópicos/temas" que emergiram durante as sessões como significativos para os componentes. Foram selecionados os temas mais representativos do fenômeno grupal, tomados como eixos norteadores da tarefa do grupo. Desse modo, as falas foram organizadas em torno de alguns núcleos temáticos, que foram posteriormente distendidos ao longo de um contínuo temporal, permitindo identificar as "etapas" de acordo com a tarefa que emergia espontaneamente do grupo.

\section{Resultados}

No decorrer dos grupos pôde-se perceber que algumas questões levantadas refletiam preocupações comuns a todos os participantes e seguiam até mesmo uma determinada ordem de ocorrência, inserida na dinâmica grupal. Estes dados aparecem sistema-

Paidéia, FFCLRP-USP, Rib. Preto, junho/99.
No decorrer de cada encontro, uma psicólo- 
tizados no Quadro 1.

Quadro 1: Diferentes etapas do processo grupal e as questōes que emergiram em cada etapa.

\begin{tabular}{lll}
\hline \multicolumn{2}{c}{ PERCURSO DO GRUPO } & \multicolumn{1}{c}{ QUESTÕES } \\
\hline $1^{\circ} \quad$ Adaptação & $\begin{array}{l}\text { O que faz um acompanhante? } \\
\text { Ansiedade gerada pela expectativa de não } \\
\text { conseguir desempenhar o papel esperado }\end{array}$ \\
$2^{\circ} \quad$ Repercussões do Diagnóstico & $\begin{array}{l}\text { Impacto inicial } \\
\text { Aceitação da doença } \\
\text { Mudanças de vida: negativas e positivas }\end{array}$ \\
& $\begin{array}{l}\text { Decisão: prós e contras } \\
\text { Complicações e efeitos adversos } \\
3^{\circ} \quad \text { Repercussões do TMO }\end{array}$ \\
& $\begin{array}{l}\text { Ansiedade pela pega } \\
\text { Ambivalência frente à alta }\end{array}$ \\
& Insegurança \\
$4^{\circ} \quad$ Medo da Recaída & Medo de terem se sacrificado em vão \\
& Dúvida quanto a repetir a experiência \\
& Crença no poder de cura da equipe \\
& Apego à religiosidade \\
Espera pelo milagre \\
Resignação: Deus sabe o que faz
\end{tabular}

superado essa fase de "adaptação" ao papel de acompanhante e que conseguiam, na maioria das vezes com extrema habilidade, auxiliar seus novos colegas, através do relato de suas próprias e similares vivências.

\section{2- Repercussões do diagnós- tico}

Incluem-se nesta categoria as reações, sentimentos, atitudes e condutas suscitadas no acompanhante e demais familiares, após a comunicação do diagnóstico.

\section{a) Impacto do diagnóstico}

Esse era sempre apontado como o pior momento, sendo que a descoberta da doença se colocava como uma linha divisória em suas vidas. É muito freqüente aqui o surgimento da metáfora de uma BOMBA, bomba esta que veio do nada, destruiu tudo o que havia sido construído e o que se planejava construir.

"Parece que uma bomba caiu na minha vida, sabe bomba mesmo, dessa que destrói tudo, deixa só restos, fica tudo em cacos... e a gente olha aquela bagunça e não sabe nem por onde começar a arrumar as coisas..." (A, tia)

\section{b) Aceitação da doença}

A aceitação da doença é um processo gradual, que em geral evolui desde a negação da condição patológica até sua assimilação e resignação. A comunicação do diagnóstico era acompanhada sempre de sentimentos de revolta ou indignação. Em algumas falas, fica patente a referência à idéia de castigo:

“...fico pensando por que com a gente? Com tanta gente ruim no mundo... por que nós? Nunca fizemos mal a ninguém. Isso não é justo!" (L, esposa)

$\mathrm{O}$ fato de atribuírem ao paciente qualificações predominantemente positivas é outra característica dessa etapa. 
“...por que isso foi acontecer com ele, sempre tão bom? Não tinha vício nenhum, trabalhador, vai ver que pegou essa doença de tanto trabalhar." (P, filha)

Superada essa fase de revolta, geralmente vinha a aceitação propriamente dita da enfermidade, o que possibilitava partir para a construção de estratégias de enfrentamento:

"Também agora não adianta pensar no porquê das coisas, do porquê que foi ele... temos é que fazer alguma coisa, é hora de lutarmos contra isso." (K, esposa)

\section{c) Mudanças decorrentes do diagnóstico}

Segundo os sujeitos, as modificações decorrentes da doença foram tanto positivas como negativas. As mudanças positivas mais freqüentemente referidas se deram no plano psicológico, uma vez que a doença contribuiu para uma maior aproximação entre os familiares:

"Sabe que essa doença dele acabou unindo mais a família... No início foi muito dificil, mas agora parece que estamos mais juntos, mais unidos. Agora acho que somos uma família mesmo, sabe?" (F, esposa)

$O$ episódio da doença também levou os familiares a repensarem e modificarem seus valores e até receberem apoio de pessoas de quem jamais esperariam tal atitude solidária. Essas mudanças eram tão profundas que às vezes chegaram a interferir em questões até então tidas como dogmas, verdades incontestáveis, como o exemplo de uma paciente que fez a seguinte colocação:

"Eu me decepcionei muito com o pessoal de minha igreja... vieram me dizer que eu não podia deixar o meu marido tomar sangue. Vê se pode? Eu é que vou perder meu marido, quero ver o que essas pessoas fariam se estivessem em meu lugar... Na hora que mais precisava deles me fazem isso... Depois de tudo isso passado eu vou repensar essa minha decisão... vou conversar com eles... não sei se quero continuar... justo eu que era tão fanática." ( $\mathrm{C}$, esposa)

3- Repercussões do transplante de medula óssea Essa categoria engloba a decisão de se realizar o TMO e as implicações decorrentes desse pro- cedimento:

\section{a) Decisão de realizar o TMO}

A decisão de se fazer o transplante era sempre permeada por conflitos, sendo que o acompanhante se sentia muito responsável pela decisão do paciente, independentemente de ter expressado sua opinião. Se opinava, acreditava ter induzido o familiar a tomar tal decisão:

"Eu falei para ela que no seu lugar eu faria... agora fico pensando: será que eu devia ter falado isso? E se não der certo?" (M, marido)

Evitava emitir sua opinião, sentia que fora omisso e acreditava (caso sua opinião fosse contrária a fazer o TMO) que poderia ter impedido o "pior". Deste modo, independentemente de se posicionar frente à realização do TMO, o acompanhante se sentia, de algum modo, responsável ("culpado") pelo destino do paciente.

“...eu desde o início tinha a minha opinião, por mim não fazia. Mas eu não falei isso para ele não. Mas se algo der errado eu também vou ficar me sentindo culpada, porque eu podia ter evitado isso..." (F, esposa)

Essa decisão tornava-se ainda mais difícil nas situações em que o doente era menor de idade, cabendo aos pais a responsabilidade total.

"Nunca vi uma coisa tão difícil de se fazer.. a gente tem que decidir pela vida de uma criança, filho da gente... E o pior é que a gente ainda coloca outro filho nessa estória (o doador)... Se eles fossem maior, a gente não tinha tanta responsabilidade..." (G, mãe)

Em suma, nota-se uma profunda ambivalência diante de um procedimento que pode tanto "dar" a vida ("curar"), quanto a morte.

\section{b) Complicações e implicações do procedimento}

$O$ aparecimento de tais complicações era responsável por manifestações de arrependimento por parte dos familiares, que acreditavam que o paciente estava muito melhor, fisicamente, antes do procedimento. Nesses momentos, o tratamento amedrontava mais do que a própria doença.

Além dessas possíveis complicações, o uso de uma quimioterapia intensiva acarretava também 0 aparecimento de alguns efeitos colaterais, tais 
conio:

Alopecia: A reação inicial à queda do cabelo era muito negativa, principalmente se o paciente fosse do sexo feminino. Mas, devido talvez ao fato deste ser o efeito colateral mais conhecido e esperado da quimioterapia, era uma realidade com a qual os acompanhantes adaptavamse com uma certa habilidade.

"...quando eu vi ele daquele jeito levei um susto... mas eu me acostumei logo. Já tinha visto pessoas aqui carecas, e depois o cabelo cresce de novo e isso é o de menos..." ( $\mathbf{Q}$, namorada)

$>$ Mucosite: Trata-se da não renovação das mucosas oral, esofágica e gástrica, como efeito colateral da quimioterapia em altas doses. Os acompanhantes desde o início do tratamento temiam muito o aparecimento dessa fase. Quando essa enfim surgia, ficavam muito ansiosos e se sentiam muito impotentes, uma vez que em nada poderiam ser úteis ao paciente, que não conseguia falar, nem ingerir nada. Lembravam dessa fase como sendo um dos mais difíceis momentos do tratamento.

“...que desespero... e se eu pudesse fazer alguma coisa... ver um filho assim sem poder comer, sem beber, com muita vontade de beber água, sem falar... e a gente fica assim, sem poder fazer nada... Se pudesse eu pegava para mim todo esse sofrimento dele" (E, pai)

Os acompanhantes relatavam mudanças em alguns de seus valores, colocando que a partir daquele momento passariam a valorizar mais alguns aspectos do cotidiano:

“...eu depois dessa experiência vou passar a valorizar coisas que antes eu fazia toda hora e não sabia da importância delas... Agora toda vez que eu beber um copo de água, toda vez que eu comer alguma coisa que eu tenha vontade, eu vou lembrar de agradecer a Deus por isso." (A, tia)

\section{c) Ansiedade pela pega}

No período da aplasia, entre a infusão e a pega da medula, o risco de infecção é elevado. Devido ao fato de perceberem o paciente extremamente fragilizado e indefeso, esse era um momento de grande tensão para os acompanhantes, sendo frequientes as manifestações de ansiedade, acompanhadas por reações de choro, insônia, impaciência e medo.

O fim desse tormento vinha com a notícia da pega ou enxertamento da medula óssea, momento em que começam a aparecer os primeiros indícios do funcionamento da medula: inicialmente um progressivo aumento dos granulócitos, seguido pelo aumento de plaquetas e o reaparecimento de reticulócitos. A confirmação da pega é obtida por meio de estudos citogenéticos ou através de detecção de marcadores genéticos no sangue, com características de proliferação de células do doador (Pasquini, 1991).

Com a confirmação da pega, as mudanças ocorridas nos acompanhantes eram evidentes. A sensação que relatavam era a de terem sido recompensados por um enorme sacrifício:

“...Hoje foi o dia mais feliz da minha vida... O doutor falou que a medula pegou... Até que enfim, eu já não agüentava mais essa espera..." (G, mãe)

\section{d) Ambivalência frente à possibilidade da alta}

Após a notícia da pega, os acompanhantes tratavam de providenciar os últimos preparativos para a saída dos pacientes da enfermaria e aguardavam ansiosamente esse momento. Depois de passada a euforia inicial da possibilidade de se libertarem do isolamento imposto pelo tratamento, a notícia da alta não soava mais como algo tão positivo: vinha a insegurança de não serem capazes de cuidar do paciente sem o apoio da equipe. Os conflitos aqui vivenciados eram semelhantes aos da primeira fase.

"... agora nós vamos para a casa do Grupo de Apoio ao Transplantado de Medula Óssea $(G A T M O)$... eu estou feliz pelo fim do tratamento... mas dá um medo de não conseguir controlar ela, dar os remédios para ela, fazer ela seguir as ordens dos médicos." (M, marido)

A ambivalência frente à possibilidade da alta é representada, assim, pela presença simultânea de duas tendências antagônicas: desejo versus medo de deixar o ambiente hospitalar, que é vivenciado, a um só tempo, como sufocante e protetor. 


\section{4- Medo da recaída}

Essa era uma questão que preocupava imensamente todos os acompanhantes e que, apesar de aparecer desde os primeiros encontros, manifestava-se com uma freqüência crescente à medida em que o tratamento se aproximava da reta final. Isto porque depois de terem vivenciado todas as dificuldades decorrentes do transplante, não suportavam pensar na possibilidade do tratamento não ser efetivo. Aqui eram freqüentes as colocações de que, se fosse necessário, não sabiam se suportariam tudo novamente.

“...depois de ter passado por tudo isso, nem quero pensar que ainda existe uma chance das coisas não darem certo... da doença voltar.. não sei se eu conseguiria passar de novo por isso..." (N, mãe)

A possibilidade de recidiva da doença desencadeava, muitas vezes, sentimentos persecutórios:

"...agora qualquer dorzinha que ele tenha já vou ficar aflita pensando que a doença voltou, que vai ter que internar de novo..."(0, pai)

\section{5- A questão da morte}

Não se trata de um trabalho de elaboração fácil para o acompanhante, principalmente por se ter que lidar o tempo todo com a questão da morte, que segundo Becker (1973) assombra o animal humano como a nenhum outro.

Segundo Kübler-Ross (1992), as atitudes dos pacientes diante da morte e do morrer atravessam cinco estágios: (1) a negação e o isolamento; (2) a raiva; (3) a barganha com Deus, entendida pela autora como uma tentativa de adiamento da morte, que seria obtida através de uma espécie de "prêmio por bom comportamento"; (4) a depressão; e o último estágio: (5) a aceitação.

Ainda de acordo com essa autora, os membros da família experimentam diferentes estágios de adaptação, semelhantes aos descritos para os pacientes, sendo que em determinados momentos as reações emocionais dos familiares e dos pacientes são semelhantes.

Esses estágios de adaptação dos acompanhantes, a partir do momento em que a morte se mostrava iminente, foram detectados e serão anali- sados no presente estudo. Nesses momentos, diferentes recursos/mecanismos de defesa eram recrutados para lidar com os conflitos: no início, uma crença onipotente no poder de cura da equipe, seguida do apego à religiosidade e, por fim, a resignação diante do inevitável.

\section{a) Crença no poder de cura da equipe}

Apesar de, desde o início, o acompanhante estar ciente do risco de vida que o paciente corria, a questão da morte só aparecia quando um dos pacientes corria risco iminente de vida.

Em um primeiro momento, os demais acompanhantes acolhiam e tentavam reconfortar o acompanhante com colocações do tipo:

“...é assim mesmo, eles pioram mas depois melhoraram... Isso faz parte do tratamento... Confia nos médicos, eles são bons... Já ouvi dizer que são os melhores, acredita neles..." (Q, namorada)

E se essa crença no poder da equipe, por ventura, fosse abalada, restava um só recurso, a saber:

\section{b) Apego à religiosidade}

Mesmo nas fases terminais, os familiares precisam manter a esperança. É muito comum que busquem apoiar-se na fé como forma de conviver com o sofrimento. A decisão quanto ao futuro é colocada nas mãos de um poder superior: Deus ou alguma outra entidade suprema, que tudo sabe e que tudo pode. Valle (1991) nota que o apego à religião e ao poder da fé podem, por outro lado, assumir um papel de aliviar a angústia e contribuir para a aceitação da realidade pessoal.

No grupo investigado, a questão da religiosidade aparecia com toda ênfase, nos momentos de "crise" mais agudos, principalmente se o paciente não dava indícios de melhora. Era como se, esgotados os últimos recursos médicos, fosse necessário "apelar" para uma força maior. A vivência de desamparo fortalecia a crença em um poder supremo, reforçando o apelo que a religiosidade assume nos momentos de crise:

“... é hora de ter fé, confia que Deus pode tudo..." (G, mãe)

\section{c) Espera pelo milagre}

Paidéia, FFCLRP-USP, Rib. Preto, junho/99. 
Se mesmo assim a situação não melhorasse, o nível de ansiedade crescia e a necessidade de se acreditar em um poder superior aumentava na mesma proporção: era o momento da espera do MILAGRE:

“...as pessoas sem fé não acreditam, mas eu sei de muitos casos de pessoas que receberam verdadeiros milagres... aqui mesmo tem uma senhora que falou que o marido dela estava nas últimas, mas ela rezou muito $e$ ele melhorou... até os médicos ficaram assustados..." (H, mãe)

\section{d) Resignação: Deus sabe o que faz}

Se por acaso o "milagre" não se consumasse, o último recurso utilizado era o da resignação. É como se a luta tivesse cessado e fosse chegada a hora do repouso derradeiro do guerreiro-paciente (KüblerRoss, 1992):

“... foi tentado tudo, vocês fizeram o melhor, os médicos também... mas Deus sabe a hora de levar o seu filho..." (J, mãe )

$O$ acompanhante que estava sofrendo a perda do familiar deixava-se consolar pelo grupo, acabando por aderir também ao argumento de que:

“...Agora é entregar na mão de Deus, Ele quem sabe... Vai ver que Ele precisa mais dele do que eu, vai ver que está faltando anjos lá no céu." (E, pai )

Esse mesmo pai, logo após o óbito do seu filho, fez a seguinte colocação:

“...essas coisas não deveriam ser assim, um pai nunca devia viver mais que um filho... Mas quem sou eu para questionar os planos divinos, pelo menos esse meu filho seguiu o que Deus tinha reservado para ele, foi uma morte natural, de uma doença que ele não procurou. Deus deu para ele essa doença porque queria ele junto Dele..." (E, pai)

Nesses momentos penosos de luto, não foram poucas as demonstrações de carinho, conforto $e$ gratidão dirigidas à equipe e aos demais acompanhantes pelos familiares que acabavam de sofrer a perda.

Através dos resultados acima descritos podese constatar que o processo grupal segue um percurso "cronológico", que se inicia com a questão da adaptação à nova condição de vida introduzida pela enfermidade - nessa etapa, é freqüente o medo de não se conseguir desempenhar o papel de acompanhante, sendo comum nesse momento a busca de informações e apoio. A seguir aparecem questões referentes ao impacto do diagnóstico e à dificuldade de aceitação da doença do familiar. Nesse instante são amplamente discutidas as mudanças de vida, tanto positiva como negativas, decorrentes do "enfrentamento" dessa situação, ao mesmo tempo nova e extremamente delicada. Em um terceiro momento, discutem-se as repercussões da decisão de fazer o transplante e as vivências da enfermaria (complicações e implicações do procedimento, sentimentos de isolamento e desamparo potencializados pelo confinamento no ambiente hospitalar, ansiedade frente à pega da medula e posteriormente frente à alta hospitalar). Ao término do tratamento aparece, em geral, o medo da recaída, despertando muitas vezes sentimentos de cunho persecutório.

Um outro tema amplamente trabalhado nos grupos foi a morte, questão geralmente desencadeada pela piora ou óbito de algum paciente. Frente a um assunto tão delicado, os membros dos grupos utilizaram-se de alguns recursos e mecanismos defensivos: inicialmente se apegavam à crença no poder da equipe, depois buscavam conforto na religiosidade. Nesse momento, era muito freqüente que a esperança se traduzisse em uma expectativa de um milagre; caso este não se materializasse, fazia-se uso da resignação como último recurso para aplacar as angústias maciças de aniquilamento desencadeadas pelo contato com o inevitável da morte.

\section{Discussão}

Através dos resultados obtidos foi possível constatar que os acompanhantes sofrem angústias semelhantes às vivenciadas pelos pacientes, compartilhando com estes cada uma das dificuldades do transplante. Esse dado está de acordo com os achados de Kronenberger e cols. (1998), que detectaram a existência de uma íntima relação entre o bem-estar de familiares e pacientes, de modo que as complicações no tratamento afetavam intensamente os membros familiares.

No caso do presente estudo, os resultados sugerem que um acompanhamento psicológico sistemático junto aos familiares mostrou-se de enorme importância, proporcionando um espaço de confor- 
to psíquico e elaboração dos intensos sentimentos de culpa, desamparo e revolta que o adoecer de um ente querido normalmente desencadeia.

A técnica grupal utilizada mostrou-se valiosa como instrumento de trabalho e como recurso de aprendizagem que permite mobilizar e transformar estruturas estereotipadas ou dificuldades que surgem como processos obstrutivos na comunicação e na aprendizagem, devido às ansiedades que impedem a mudança. $\mathrm{O}$ acompanhamento sistemático ao acompanhante $e \mathrm{a}$ oferta de um espaço de continência para sua fala acaba repercutindo nas três peças básicas do processo do tratamento: acompanhante - equipe médica - paciente, uma vez que estas se encontram intimamente interligadas.

No que concerne aos acompanhantes, o grupo auxiliou-os na elaboração da dolorosa experiência do adoecimento de uma pessoa querida, o que, segundo Rolland (1998), pode desencadear respostas emocionais de ansiedade, solidão, tristeza, desapontamento, raiva, ressentimento, culpa, exaustão e desespero, reações amplamente observadas entre os participantes dos grupos.

Ainda de acordo com Rolland (1998), uma forma de os profissionais apoiarem os familiares é auxiliá-los no restabelecimento de crenças de que a situação não se encontra totalmente fora de seu controle, uma vez que a perda da sensação de controle pode ser uma experiência debilitante para a família, produzindo ansiedade ou imobilismo. Dessa forma, ajudá-la a priorizar tarefas e a tomar providências, tais como reunir informações sobre a doença e reconhecer os recursos disponíveis na comunidade, mostrou-se útil para o restabelecimento da sensação de domínio sobre os rumos de seu existir. O grupo muitas vezes supria essa necessidade, servindo como provedor de informações, ao mesmo tempo em que permitia reparar conceitos e idéias incorretas a respeito do procedimento (TMO).

Além de prover tais informações, o grupo funcionava como um espaço para a ventilação $e$ catarse dos sentimentos dos participantes, ajudando os familiares a discriminarem suas manifestações afetivas e seus temores de loucura, o que de acordo com Rolland (1998) pode diminuir a reatividade emocional que caracteriza esse estágio. De fato, observou-se que permitir aos participantes falarem livremente de suas tensões e dificuldades, comparti- lharem suas emoções com pessoas que vivenciavam a mesma situação vital e sentirem-se compreendidos e amparados por alguém da equipe, ajudava a mitigar as reações emocionais intensas próprias desse estágio (Rolland, 1998). De acordo com Hallm (1990), esses são alguns dos principais benefícios que um grupo de apoio pode fornecer a um familiar.

A observação de Romano (1999) de que um grupo de apoio a familiares traz também benefícios para a equipe pôde ser inteiramente comprovada no presente estudo. A equipe pôde usufruir dos benefícios da redução do nível de ansiedade do familiar que acompanha o paciente, uma vez que, de acordo com Higginson (1993), a ansiedade familiar é um dos componentes de mais difícil manejo para a equipe profissional. Dessa forma, através do apoio psicológico oferecido sistematicamente através do dispositivo grupal, acreditamos que seja possível aumentar a possibilidade de o acompanhante efetivamente se tornar um aliado da equipe, em vez de umproblema-a-mais-para-a-equipe.

Finalmente, os próprios pacientes parecem ter se beneficiado indiretamente dessa intervenção, uma vez que os acompanhantes se colocavam menos inseguros e menos ansiosos no contato com os mesmos. Segundo Kübler-Ross (1992), no período de doença os familiares desempenham um papel preponderante $\mathrm{e}$ as suas reações contribuem de maneira decisiva para as próprias reações dos pacientes. Isso poderia ser traduzido, no contexto do presente estudo, da seguinte maneira: uma vez que o grupo parece favorecer no acompanhante a apropriação ativa da realidade que ronda o processo do adoecer e do tratamento, tal progresso se transfere gradualmente para o relacionamento íntimo que ele mantém com o paciente, potencializando sua capacidade de continência às necessidades emocionais do mesmo.

O fato de os acompanhantes se sentirem acolhidos aumentava sua sensibilidade às necessidades emocionais dos pacientes, favorecendo o desempenho da tarefa do cuidar e acolher, contribuindo assim para o reforço de atitudes firmes (não ambígüas) e de uma atitude mais empática diante do sofrimento alheio. Esses dados vão ao encontro da constatação de Dracup (1982) de que o grupo de apoio ao familiar desencadeia modificações no cuidado oferecido, beneficiando em última instância o próprio paciente. 
Não se trata, obviamente, de um trabalho fácil, uma vez que envolve a questão delicadíssima da possibilidade de perda de um membro da família. Por outro lado, cria-se um celeiro fértil de possibilidades tanto no sentido da desconstrução de mitos e preconceitos relacionados aos cuidados dispensados ao portador de doenças crônicas e potencialmente fatais, como também de construção de novas narrativas familiares que permitam acolher e elaborar os afetos mobilizados pelo processo do adoecer. Valendo-se das potencialidades oferecidas pela práxis grupal, ofertamos um dispositivo onde os cuidados terapêuticos se voltam para o cuidar de quem cuida, uma dimensão freqüentemente negligenciada nos esquemas convencionais de tratamento.

Para arrematar essas notas finais, talvez caiba aqui uma citação do poeta irlandês W. B. Yeats, que ao nosso ver permanecerá sempre atual.

\section{"O Homem ama}

$E$ ama o que desvanece

O que mais pode ser dito?"4

Uma possível resposta a esta pergunta e que só foi capaz de ser formulada após o atravessamento da experiência do grupo de apoio, é a de que o que desvanece é o objeto amado e não a capacidade de amar. Podemos ilustrar essa hipotese com o depoimento da esposa de um paciente terminal, colhido na enfermaria do Hospital das Clínicas, em outubro de 1999:

"Aprendi que o amor e o companheirismo não adoecem nunca." (X, esposa)

\section{Referências Bibliográficas}

Bardin, L. (1977)Análise de Conteúdo. Lisboa: Edições 70, 1979.

Becker, E. (1973) The denial of death. New York: Free Press.

Chiattone E. H. B. C. (1998). Urgências psicológicas em leucemias. Em Angerami, V. A. (Org.), Urgências Psicológicas no Hospital (pp. 171192). São Paulo: Pioneira.

\footnotetext{
${ }^{4}$ No original: Man is in love / And loves what vanishes; / What more is there to say?
}

Paidéia, FFCLRP-USP, Rib. Preto, junho/99.
Dracup, K. (1982) Influence of a role supplementation program on the psychosocial adaptation of cardiac patients and spouses, Circulation, 6, p. 280.

Gayotto, M. L. C. (s/d) Movimento dialético do processo grupal. Mimeo, São Paulo, 10 p.

Hallm, M. A. (1990). Effects of support groups on anxiety of familiy members during critical illness. Heart Lung, 19(1), 62-71.

Higginson, I. (1993). Advanced cancer: aiming for the best in care. Quality in Health Care, 2, 112116.

Kronenberger, W. G.; Carter, B. D.; Edwards, J.; Morrow, C.; Stewart, J. e Sender, L. (1998). Psychological adjustment of mothers of childrens undergoing bone marrow transplantation: the role of stress, coping, and family factors. Children's Health Care, 27(2), 77-95.

Kübler-Ross, E. (1992) Sobre a morte e o morrer. (P. Menezes, Trad.). $5^{\mathrm{a}}$ ed. São Paulo: Martins Fontes.

Minayo, M. C. S. (1992) O desafio do conhecimento: Pesquisa qualitativa em saúde. São Paulo/ Rio de Janeiro: Hucitec-ABRASCO.

Osório, L. C. e cols. (1989) Grupoterapia hoje. Porto Alegre: Artes Médicas.

Pasquini, R. (1991) Transplante de medula óssea na anemia aplástica severa: estudo em 108 pacientes. Tese apresentada para o concurso de Professor Titular, Departamento de Clínica Médica, Universidade Federal do Paraná, CuritibaPR.

Pichón-Rivière, E. O processo grupal. (M. Stahel, Trad.). $5^{a}$ ed. São Paulo: Martins Fontes, 1994.

Rivera, L. M. (1997). Blood cell transplantation: its impact on one family. Semin. Oncol. Nurs., 13(3), 194-199.

Rolland, J. S. (1998). Ajudando famílias com perdas antecipadas. Em Walsh, F. e McGoldrick, M. Morte na família: Sobrevivendo às perdas (C. O. Dornelles, Trad.) (pp. 166-187). Porto Alegre: ArtMed. 
Romano, B. W. (1999). Princípios para a prática da psicologia clínica em hospitais. São Paulo: Casa do Psicólogo.

Torrano-Masetti, L. M.; Oliveira, E. A.; Santos, M. A.; Voltarelli, J. C. e Simões, B. P. (2000) Supportive group for relatives of bone marrow transplantation recipients: A psychological intervention. Em: Tandem Bone Marrow Transplantation Meetings - Abstract Book, 2000. Los Angeles-Califórnia-USA: American Society for Bone Marrow Transplantation, p. 18.

Triviños, A. N. S. (1987) Introdução à pesquisa em ciências sociais: A pesquisa qualitativa em educação. São Paulo: Atlas.

Valle, E. R. M. (1991) O discurso de pais de crianças com câncer. Em Cassorla, R. M. S. (Org.) Da morte: Estudos brasileiros. (pp. 181-194). Campinas-SP: Papirus.

Zimerman, D. E., Osório, L. C. e cols. (1997) Como trabalhamos com grupos. Porto Alegre: Artes Médicas. 